\title{
Medicina ou magia? 0 contexto cultural e religioso das práticas curativas de Hildegard von Bingen
}

\section{Medicine or magic? The cultural and religious context of Hidegard of Bingen's healing practises}

\section{Medicina o magia? El contexto cultural y religioso de las prácticas curativas de Hildegarda de Bingen}

\author{
Martin Santos Barcala* \\ Paulo Augusto de Souza Nogueira**
}

\begin{abstract}
RESUMO
O presente artigo é uma investigação do tema da magia e religião popular nas obras de Hildegard von Bingen, teóloga, mística visionária e monja beneditina do século 12 . O objetivo é demonstrar como a magia articula a interação entre Hildegard e a religião popular de sua época, borrando as fronteiras ortodoxas de sua reflexão teológica, que ora condena a prática da magia, ora se imiscui em rituais que em nada diferem daqueles praticados por magos, bruxas ou feiticeiros.

Palavras-chave: Hildegard von Bingen; magia; religião popular; medicina popular; teologia sapiencial.
\end{abstract}

\begin{abstract}
This article surveys the theme of magic and popular religion in the works of Hildegard of Bingen, theologian, visionary mystic and Benedictine nun of the 12th century. The objective is to demonstrate how magic articulates the interaction between Hildegard and the popular religion of his time, blurring the orthodox boundaries of his theological reflection, which sometimes condemns the practice of magic, sometimes gets involved in rituals that are no different from those practiced by magicians, witches or sorcerers.

Keywords: Hildegard von Bingen; magic; popular religion; popular medicine; sapiential theology.

RESUMEN

Este artículo es una investigación sobre el tema de la magia y la religión popular en los trabajos de Hildegarda de Bingen, teóloga, visionaria mística y monja benedictina del siglo 12. El objetivo es demostrar cómo la magia

articula la interacción entre Hildegarda y la religión popular de su tiempo, difuminando los límites ortodoxos de su reflexión teológica, que a veces condena la práctica de la magia, otras veces interviene en rituales que no son diferentes de los practicados por los magos, brujas o hechiceros.

Palabras clave: Hildegarda de Bingen; magia; religión popular; medicina popular; teología sapiencial.

* Docente da Faculdade de Teologia da Universidade Metodista de São Paulo (Umesp), onde realiza doutoramento em Ciências da Religião no Programa de Pós-graduação (PPGCdR/Umesp).

** Professor pesquisador do PPG-Ciências da Religião da PUC-Campinas, bolsista produtividade CNPq, nível 2. Este artigo foi escrito no âmbito da pesquisa do projeto "O cristianismo primitivo como religiosidade popular do Mediterrâneo”, financiado pela FAPESP.
\end{abstract}




\section{Introdução}

Este artigo é resultado de pesquisas sobre religião popular e magia no contexto do cristianismo medieval. Trata-se de uma investigação do tema conforme se manifesta a vida e obra de uma importante teóloga, mística visionária e escritora do século 12, Hildegard von Bingen. Os referenciais teóricos adotados discorrem sobre o contexto europeu da baixa Idade Média, privilegiando autores e autoras cujas análises lançam luz para as práticas mágicas e religiosas na cultura popular. Mas a pesquisa procurou manter o foco na relação entre religião, medicina e magia na cultura e religião popular na Alemanha do século 12, a partir de duas obras da abadessa: o Scivias (Conhece os caminhos do Senhor) e o Physica (Livro de Medicina Simples).

No primeiro tópico, buscou-se apresentar um brevíssimo relato biográfico de Hildegard, enfatizando a dinâmica peculiar de suas produções teológicas, bem como destacando a recepção posterior de sua vida e obra, que culminou com sua canonização pelo Papa Bento XVI, em 2012.

Em seguida, o tema da magia e da cura são analisados a partir de trechos das visões da abadessa contidas no Scivias, revelando como seu tratamento ambíguo da magia pode ser compreendido no contexto do hibridismo da religião popular de seu contexto e das estratégias adotadas por missionários cristãos na Alemanha nos séculos anteriores. Ainda neste tópico, são resumidas as orientações de Hildegard para a cura da alma enfermada por uma vida de vícios, evidenciando a centralidade do tema da cura em seus textos. Nesse contexto, Hildegard parece acompanhar as recomendações canônicas já disponíveis em seus dias, prescrevendo obediência a virtudes materializadas por práticas penitenciais.

No terceiro e último tópico, são analisados os rituais de cura prescritos por Hildegard em seu Physica. Devido à abundância de material contido naquele compêndio, optou-se pela seleção de alguns exemplos que guardam enormes semelhanças com rituais de magia preservados tanto em textos da Antiguidade, como os Papiros Mágicos Gregos (PMG), quanto com as formas culturais disponíveis na religião popular do período e contexto em que viveu a monja. O resultado da pesquisa indica a possibilidade de se reler a obra daquela que atualmente é uma sancta et magistra integrante da devoção institucional católico-romana numa chave que destaca a indistinção entre religião, magia e medicina em seu pensamento e prática. Isto só é possível, contudo, pela consideração de sua atuação como agente cultural que interage intensamente com a cultura e religião popular, transitando igualmente pelos estratos mais elevados de sua sociedade. 


\section{Hildegard von Bingen em seu contexto e na recepção posterior de sua vida e obra}

Hildegard von Bingen (1098-1179) é reconhecida no âmbito da reflexão teológica principalmente por suas experiências visionárias, que resultaram na composição de extensas obras cujo conteúdo apresenta uma versão da dogmática cristã, tributária da exegese alegórica do período patrístico, mas com ênfases muito peculiares. Hildegard reivindicava inspiração divina tanto para as visões quanto para as explicações e comentários acrescidos a elas. As três obras oriundas de suas visões e que constituem o que pode ser considerado sua "trilogia" teológica são: o Scito vias Domini (ou Scivias, que pode ser traduzido como "Conhece os Caminhos do Senhor"), escrito entre 1141 e 1151; o Liber vitae meritorum (Livro dos méritos da vida ou Livro da vida meritória); e o Liber divinorum operum (Livro das obras divinas), concluído por volta de 1173 .

Desde sua infância, Hildegard demonstrava possuir dons pouco convencionais. Aos cinco anos de idade, conseguira prever a cor de um bezerro ainda no útero da vaca, para espanto de sua babá. O fato seria irrisório e sem nenhuma importância se a mesma capacidade premonitória não tivesse se estendido para eventos e situações mais complexas e relevantes. Todavia, como a previsão de acontecimentos futuros fora se tornando frequente na vida de Hildegard, isso pode ter colaborado para a decisão de seus pais em consagrarem-na à vida religiosa, entregando-lhe aos cuidados de Jutta, abadessa responsável pela seção feminina do mosteiro de Disibodenberg (NEWMAN, 1997, p. 7-8). ${ }^{1}$

As revelações de Hildegard continuariam acontecendo durante o restante de sua vida, seguindo quase sempre o mesmo padrão. Contudo, apenas em 1141, quando já tinha quarenta e dois anos de vida, Hildegard decidira publicar o conteúdo de suas visões. Porém, diferentemente das ocasiões relatadas em sua infância e adolescência, agora a monja afirmava que tais visões esclareciam-lhe "o significado da explicação das Escrituras, isto é, do Saltério, do Evangelho e de outros livros católicos, tanto do Antigo quanto do Novo Testamento" (HILDEGARD, 2015, p. 96). Esta afirmação, contida na "declaração de abertura" do Scivias, é acompanhada de uma narrativa sobre a natureza divina de tais revelações, obtidas através de experiências visionárias nas quais Hildegard testificava ver e ouvir reflexos da "Luz vivente" projetados em sua própria alma, como se na superfície de um lago.

\footnotetext{
1 Para as demais informações biográficas de Hildegard, cf. a obra de Barbara Newman (1997) indicada na bibliografia ao final, especialmente as páginas 1-15.
} 
A dinâmica de tais experiências fora detalhada por ela - na época já abadessa de um mosteiro exclusivamente feminino fundado por ela em Rupertsberg - em uma carta a Guibert de Gembloux (1124-1214), abade responsável pela região em que estava o mosteiro fundado por Hildegard. Dentre outros detalhes, Hildegard enfatiza suas limitações culturais e acadêmicas, sua ignorância quanto ao latim clássico e erudito, e assume o epíteto que será recorrente nas duas outras obras subsequentes da mesma natureza já mencionadas: femina indocta. ${ }^{2}$ Assim sendo, todo conteúdo das revelações é atribuído diretamente à inspiração divina, o que concede a Hildegard não apenas autoridade para publicar suas visões, mas também pode ser visto como salvoconduto contra acusações de adivinhação, prática duramente combatida por ela no Scivias, mesmo que essencialmente indistinta de suas próprias experiências, como se verá a seguir.

Outro dado curioso na referida correspondência remetida a Guibert de Gembloux é a insistência de Hildegard quanto à persistência das visões - que, de acordo com ela, ocorriam desde os seus três anos de idade - e do seu próprio estado de consciência no momento em que tais experiências aconteciam:

Eu não as escuto com meus ouvidos exteriores, nem as percebo com os pensamentos de meu coração ou por qualquer combinação de meus cinco sentidos, mas apenas em minha alma, enquanto meus olhos exteriores estão abertos. Assim, nunca fui presa do êxtase nas visões, mas eu as vejo bastante consciente, dia e noite (HILDEGARD apud NEWMAN, 1985, p. 165).

A argumentação de Hildegard é interessante para a presente pesquisa não porque reivindica inspiração divina para o conteúdo de suas obras, mas exatamente porque esta reivindicação também se presta à defesa de possíveis acusações contra a abadessa que a vinculariam à prática da magia em seu contexto, a saber: a adivinhação e o culto aos demônios, fortemente marcado pelo êxtase. ${ }^{3}$

Antes mesmo da conclusão do Scivias, Hildegard enviou os manuscritos para o renomado místico beneditino Bernardo de Claraval (1091-1153), com

\footnotetext{
2 A autodepreciação de Hildegard precisa ser considerada à luz da intensa misoginia de sua época, bem como da proibição eclesiástica que impedia as mulheres atuarem publicamente. A postura da abadessa pode revelar, portanto, uma "estratégia discursiva" para driblar tais impedimentos (cf. NEWMAN, 1985). Para um estudo comparativo entre Hildegard e dos demais autores eruditos de sua época, veja o interessante artigo de Jeroen Deploige (1999).

3 Sobre a relação entre culto aos demônios, adivinhação e magia no contexto da Alemanha do século 12, veja a obra de Richard Kieckhefer (2014, p. 43-55), Catherine Rider (2006, p. 1-13 e 29-75) e Albrecht Classen (2017, p. 26-38).
} 
quem mantinha intensa correspondência. Este, por sua vez, encaminhou os textos ao Papa Eugênio III (1088-1153), manifestando sua profunda admiração e reverência pelos dons da abadessa. O Papa, reunido em concílio com bispos da região de Tréveris, leu os manuscritos em público e, igualmente impressionado com seu conteúdo e os dons de Hildegard, concedeu a ela o reconhecimento destes dons e autorização não apenas para publicar aquela obra, mas também pregar publicamente, empreender viagens missionárias e atuar para fora dos limites de seu convento, fato que mudaria decisivamente o anonimato mantido por Hildegard e o ocultamente de suas visões (HILDEGARD, 2015, p. 27-35).

Nas décadas seguintes à benção apostólica do Papa Eugênio III, Hildegard terá uma produção profícua e diversificada. Além das três obras resultantes de suas experiências visionárias, a abadessa comporá um drama musical intitulado Ordo Virtutum, incluído no final do Scivias - e que lhe renderia fama e reconhecimento artístico até os dias atuais -; um numeroso epistolário contendo suas correspondências com indivíduos de todas as classes sociais, abrangendo desde papas, imperadores e governantes até gente simples como uma mulher denominada Sibila, cuja carta é objeto de análise posterior neste artigo; um instigante e misterioso manual sobre um idioma desconhecido - que mistura latim e germânico - e que ela considerava igualmente revelado, intitulado Lingua ignota; e dois volumes dedicados à medicina popular: Physica e Causae et Curae. O primeiro destes volumes será analisado com mais detalhes no último tópico desta pesquisa.

A ênfase nos aspectos femininos que Hildegard imprime às descrições de suas visões - ouvidas por ocasião das mesmas experiências místicas já relatadas - conjugada com a valorização do corpo e da natureza, faz com que sua reflexão se aproxime significativamente da tradição teológica sapiencial (NEWMAN, 1997, p. 42-88). ${ }^{4}$ No entanto, foi pelas suas capacidades de curar e realizar exorcismos que Hildegard adquiriu fama entre seus contemporâneos, a ponto de ter sua canonização pleiteada já pouco tempo após sua morte.

Isto ocorreu apenas no ano de 2012, quando o Papa Bento XVI promulgou a canonização de Hildegard von Bingen e, posteriormente, concedeu-lhe também o título de "Doutora da Igreja". De acordo com Bento XVI, "a doutrina hildegardiana é considerada eminente tanto pela profundidade e retidão das suas interpretações, como pela originalidade das suas visões" (BENTO XVI, 2012, \3). Estes dois títulos sintetizam e, de certa forma,

4 Barbara Newman estabelece o que chama de "teologia do feminino" como chave de leitura para as obras de Hildegard que, segundo ela, estaria enraizada numa tradição teológica sapiencial que atravessa as narrativas bíblicas e encontra forte expressão a partir do século 9. 
tentam harmonizar definitivamente os aspectos nem sempre convencionais da vida e obra da agora sancta et magistra Hildegard. Santa por seus milagres e doutora por seus ensinos, a investigação mais cuidadosa e imparcial de seus textos revela que, na verdade, a abadessa exercera um importante papel de agente cultural intermediário entre a cultura e religiosidade popular presentes em seu contexto no século 12 e a crescente dogmatização ortodoxa do cristianismo europeu na Idade Média. Para demonstrar este fato, que nunca ocorre isento de tensões e estratégias de dissumulação, este artigo analisará o tema da cura e da magia no Scivias e no Physica.

\section{Magia e cura no Scivias}

$\mathrm{Na}$ mais conhecida de suas obras, o Scivias, Hildegard aborda o tema da magia de forma direta na terceira visão do primeiro livro, quando discorre sobre o "universo e seu simbolismo". À primeira vista, a posição de Hildegard a respeito das práticas mágicas é bastante ortodoxa, no sentido de compreendê-las como obra diabólica e, portanto, absolutamente condenáveis. Suas invectivas começam por classificar como "pagãos", "hereges" e "falsos profetas" aqueles que iludem as pessoas por meio de "falacioso engano", que consiste em "querer saber o que não lhes cabe saber, imitando aquele que ansiava por ser como o Altíssimo". Estes estão afastados de Deus, pois "amam as sendas estranhas, buscando as coisas falsas que uma criatura insensata lhes mostra acerca de acontecimentos futuros" (Scivias I, 3:19).

Os tais seriam praticantes de uma "arte perversa", mais pelas suas características desafiadoras da soberania divina do que por qualquer outra coisa. Assim, ao mesmo tempo em que condena, Hildegard também abre concessões, sempre anunciando as sentenças divinas em primeira pessoa:

Ó desgraçados! Será que às vezes não permito que as criaturas vos mostrem o que acontecerá? Elas podem mostrar-vos estes sinais, porque elas me temem, a Deus, como um servo pode às vezes mostrar o poder de seu senhor, e tal como o boi, o asno e outros animais mostram a vontade de seus donos, quando fielmente obedecem seus comandos (Scivias I, 3:20).

Reconhecendo que o discernimento de revelações é inerente aos astros e demais criaturas, Hildegard situa a perversidade da magia exclusivamente no desprezo do Deus criador por parte de suas criaturas, de modo bastante semelhante às teologias monoteístas pagãs dos primeiros séculos e à estratégia dos primeiros missionários cristãos que atuaram em seu contexto: 
Ó tolos! Quando vós me relegais ao esquecimento, sem contemplar-me nem adorar-me, mas olhando para uma criatura que vos é submissa, por causa do que ela prognostica e mostra, então vós estais teimosamente deixando-me de lado, cultuando a frágil criatura em vez de vosso Criador (Scivias I, 3:20).

Detalhando um pouco mais os adversários divinos praticantes de magia, a visão-audição prossegue:

(...) por que adoras aquela criatura que não pode consolar-te nem ajudar-te, e que não pode fazer-te prosperar na felicidade, apesar de se dizer que eles podem ser astrólogos, professores da morte e seguidores de descrença pagã, que dizem que os astros vos dão vida, a vós, humanos, e determinam todas as vossas ações? Ó miseráveis, quem fez os astros? (Scivias 1, 3:20).

E, para que não fique dúvidas sobre o elemento desviante da magia, o tópico é concluído com a seguinte salvaguarda da mística cosmológica típica da teologia sapiencial: "Todavia, às vežes, com minha permissão, os astros, mediante determinados sinais, realmente manifestam a si mesmos à humanidade" (Scivias 1, 3:20). ${ }^{5} \mathrm{Um}$ dos exemplos desta manifestação astrológica teologicamente compatível se encontra na própria encarnação do Filho de Deus, que "foi mostrada por uma estrela" (Scivias 1, 3:21).

Neste ponto, fica evidente o recurso de Hildegard a uma estratégia bastante adotada pelos missionários cristãos na Alemanha a partir do século 10, ou seja, combater os praticantes das religiões pagãs acusando-lhes de adoradores de demônios. ${ }^{6}$ No entanto, como os rituais praticados pelos "magos" pagãos persistiam na religião popular, estes missionários passaram a admitir tais práticas, desde que cristianizadas, apresentando a si mesmos como continuadores das práticas pagãs e elaborando narrativas sobre vidas de santos e mártires que diferiam muito pouco neste quesito daquelas presentes na literatura pagã e popular. Tem-se, portanto, que "mago" é o agente externo de determinada tradição religiosa cujas práticas não se distinguem facilmente daquelas admitidas por esta tradição.

Da perspectiva da teologia cristã, Richard Kieckhefer denomina este processo de "acomodação" da cultura e religião popular a uma incipiente ortodoxia cristã (KIECKHEFER, 2014, p. 44-45). Já para Christoph Galle, esta interação põe em evidência o movimento de "inculturação" (Inkulturation) da religião popular pela "sanção [Sanktionierung] da magia e outras práticas

\footnotetext{
5 Os grifos são nossos e servem para destacar a ambiguidade com que Hildegard aborda o tema, mesmo em uma obra inegavelmente alinhada com as principais doutrinas eclesiásticas de seu tempo.

6 Para uma descrição da gênese desta estratégia já nos monoteísmos pagãos da Antiguidade e de sua posterior cristianização pelos Pais da Igreja, cf. o artigo de Kyle A. Fraser (2009).
} 
pagãs" pelo cristianismo aliado aos governantes locais (GALLE, 2017, p. 249-257). As teses de ambos autores justificam, pois, o tratamento ambíguo despendido por Hildegard à magia, especialmente à adivinhação, no Scivias.

Existe ainda, mais um elemento a ser acrescentado ao binômio "magia" e "religião" no contexto da Alemanha no século 12: as práticas terapêuticas ou curativas que constituem os primórdios da medicina moderna. Catherine Rider explica que, só quando tomados conjuntamente, estes três elementos são adequadamente compreendidos, pois são os efeitos terapêuticos e curativos de alguns rituais que permite distingui-los de outras práticas classificadas, a partir daquele momento, como "magia prejudicial" (harmful magic). (RIDER, 2006 , p. 6). Rider ainda acrescenta que, a partir do século 13, alguns escritores cristãos passaram a admitir outro tipo de "magia", ao lado dos rituais milagrosos causados por Deus e das práticas prejudiciais relacionadas aos demônios. Trata-se da "magia natural", "que operava por meio de forças escondidas ou 'ocultas', que não podiam ser explicadas, mas eram, de qualquer modo, cridas como sendo naturais" (RIDER, 2006, p. 10).

De certo modo, as prescrições de Hildegard no Physica poderiam se enquadrar nesta distinção, o que faria a tese de Rider recuar pelo menos um século e justificaria os rituais de Hildegard como prática já admitida pelo cristianismo de sua época. Porém, não se deve perder de vista que a classificação de Rider é por demais sofisticada e pertence ao universo teológico acadêmico. Hildegard interage e atua principalmente no campo da cultura popular, apesar de transitar por estratos mais elevados de sua sociedade. São estas interações e trânsitos que enriquecem o estudo da teologia de Hildegard e estabelecem a magia como tema de articulação dos saberes e práticas da religião popular com o cristianismo ortodoxo.

Ainda é importante considerar um último tópico do Scivias antes de se avançar para a discussão dos rituais prescritos no Physica: o modo como a cura é abordada. No Scivias, enfermidade e cura são relacionadas aos estados da alma e só trazidas para a dimensão corporal como efeito secundário. Tudo que afasta a alma de Deus é considerado "vício" e potencialmente danoso para sua saúde. A cura das enfermidades causadas por uma vida de vícios é a conversão para a prática das "virtudes". Curiosamente, não há qualquer menção direta à agência divina ou sobrenatural neste processo, cabendo à alma "ouvir" as vozes das virtudes, cujos conselhos a afastarão gradativamente dos vícios que lhe adoeceram. ${ }^{7}$

\footnotetext{
Cf. a este respeito a décima terceira visão do terceiro livro do Scivias (III, 13: 9), que contém a Ordo virtutum. Para uma análise mais detalhada das enfermidades da alma e sua cura em Hildegard, cf. o artigo de Maria Carmen Goes Martiniano de Oliveira (2013).
} 
As prescrições de Hildegard para a alma seguem o que Catherine Rider nomeia como "recomendações teológicas" ou "canônicas", aplicáveis inclusive para causas "não-físicas" de enfermidades diversas: "Consequentemente, métodos 'não-físicos' poderiam ser requeridos para solucionar o problema, e muitos canonistas [canonists] recomendavam oração, esmolas e outros exercícios devocionais" (RIDER, 2006, p. 8). Não obstante, quando o assunto é o corpo e as mazelas que lhe sucedem durante a existência, Hildegard se afastará consideravelmente de tais prescrições, privilegiando a magia disponível na religiosidade popular.

\section{Magia e cura no Physica}

Além de ter experiências visionárias, Hildegard também se dedicava aos estudos e práticas de medicina popular, tendo escrito pelo menos dois compêndios a respeito do tema: Physica - ou "Livro de Medicina Simples" - e Causae et Curae - ou "Livro de Medicina Holística (ou Composta), contendo as causas das enfermidades e seus remédios". Diferentemente das obras resultantes das visões, para esta literatura a abadessa não reivindica inspiração divina. Talvez porque, aqui, ocorre uma mudança significativa nos métodos empregados na busca da restauração da saúde. Enquanto nas obras resultantes das visões, Hildegard atrela terapia e virtude, nas obras de conteúdo descritivo de práticas terapêuticas medicinais e populares, a abadessa admite rituais que se assemelham enormemente às práticas mágicas da Antiguidade e que ainda permaneciam na cultura popular de seu contexto, jamais sendo eliminadas pelo processo de cristianização.

Deste modo, a atuação de Hildegard como agente cultural entre a cultura popular e a ortodoxia teológica é bastante evidenciada. Tome-se como exemplo sua correspondência com uma mulher simples chamada Sibila, que acorrera ao convento em busca de consolo por situações pessoais e familiares. Numa das cartas enviadas para a mulher, Hildegard se expressa da seguinte maneira:

Sibila, obra do dedo de Deus, fortaleça seu modo instável de viver, e não se submeta à agitação mental. Você não pode se escusar por estes modos, pois Deus discerne todas as coisas. Mas Deus não me ordenou explicar seus juízos sobre ti, mas, ao invés, orar por ti, porque algumas pessoas estão agora espreitando por vingança contra o que seus parentes fizeram. Pois algumas vezes Deus estende seus castigos até a terceira e quarta gerações. Mesmo assim, confie no Senhor que te livrará da espada de seus inimigos, mesmo que sua filha tenha sido capturada por eles. Eu, no entanto, falo mais sobre a salvação das almas do que sobre o destino dos homens, então, comumente não digo nada sobre estas coisas. Pois o Espírito Santo não derrama revelação para confundir os crimes das pessoas, mas 
apenas para seu julgamento. Que Deus te estabeleça no campo de vida em que você possa viver para sempre. ${ }^{8}$

Note, no trecho destacado, o que pode ser uma estratégia sutil de revelar o desencadeamento dos eventos que tiram a paz da pobre Sibila, mesmo que, concomitantemente, afirmando com ênfase o contrário, ou seja, que a vocação concedida por Deus à monja não dizia respeito à prática de adivinhações. Estas estratégias discursivas são abundantes em muitas obras de Hildegard, especialmente no Scivias. As sutilezas adotadas por Hildegard para dissuadir Sibila de seu interesse por prever o desfecho das encrencas nas quais sua família estava envolvida desaparecem quando esta última lhe escreve novamente, desta vez queixando-se de uma moléstia envolvendo hemorragias:

Confie em Deus. Mas, coloque estas palavras ao redor de seu peito e seu umbigo, no nome daquele que ordenou todas as coisas corretamente: "No sangue de Adão a morte se levantou; no sangue de Cristo a morte se acorrentou. Naquele mesmo sangue de Cristo eu te ordeno, sangue, cesse seu fluxo".?

Barbara Newman destaca que este feitiço se estabelece nas fronteiras entre a teologia sacramental e a magia, relação bastante típica no que ficaria conhecido como "teologia sapiencial", corrente da qual Hildegard é uma das principais expoentes e que privilegia a reflexão sobre o corpo e a natureza como fontes da revelação divina ou como instâncias especiais para se acessar um sentido oculto de partes do conteúdo relevado pelos meios tradicionais, que no cristianismo incluem as Sagradas Escrituras e o ensino dos Pais da Igreja.

As conclusões de Newman podem ser justas, quando se considera a obra de Hildegard exclusivamente numa moldura da história institucional da teologia cristã. Todavia, são consideravelmente precárias e insuficientes quando a moldura é ampliada para a religião popular e suas misturas de paganismo e cristianismo jamais resolvidas, principalmente no contexto da Alemanha do século 12. A evocação do sangue de Cristo para curar uma hemorragia - cura por semelhança - sugere um princípio muito comum nas práticas mágicas. Assim sendo, ao invés da suposta "teologia sacramental", Hildegard pode estar operando na lógica do hibridismo da religião popular de seus dias e, semelhantemente aos primeiros missionários cristãos em seu contexto, negociando a eficácia da magia pela substituição do sangue de animais pela invocação do sangue do "cordeiro de Deus".

\footnotetext{
Cf. NEWMAN, 1987, p. 32, os grifos são nossos.

Cf. NEWMAN, 1987, p. 33
} 
Além desta ocorrência encontrada em suas correspondências com pessoas comuns, isto é, desprovida de títulos ou status social de nobreza - meio pelo qual a abadessa pode ter tido acesso privilegiado ao cabedal de práticas e saberes oriundos da cultura popular -, muitas outras prescrições que se assemelham surpreendentemente com as práticas mágicas presentes na Antiguidade podem ser encontradas nas obras de Hildegard dedicadas ao cuidado terapêutico e pastoral daqueles que iam até ela em busca de alívio e socorro.

Para demonstrar este fato, é necessário considerar o conteúdo de sua obra posteriormente intitulada Physica, mas para a qual Hildegard escolhera o sugestivo título de "Sutilezas das diversas qualidades das coisas criadas". ${ }^{10}$ Enquanto o título mais tardio aproxima os textos do que seriam os rudimentos da medicina moderna, a escolha de Hildegard está em perfeita sintonia com a moldura teológica dentro da qual as práticas mágicas remanescentes na cultura popular são assimiladas, num processo "fagocitante".

O livro é composto por nove seções, cada uma dedicada a um "elemento" diferente: plantas; elementos (tomados numa acepção bastante peculiar do termo, que inclui ar, água, terra, o mar, os rios, dentre outros, mas deixa de fora o fogo); árvores; pedras; peixes; pássaros; animais; répteis; e metais. De um modo sucinto e instrutivo, Priscilla Throop enfatiza que "a palavra 'sutilezas', usada no título escolhido por Hildegard, faz referência aos poderes secretos ocultos nas criaturas naturais para o uso do ser humano, que são revelados por Deus" (HILDEGARD, 1998, p. 5). Note-se, mais uma vez, a indistinção entre magia, medicina e religião. Este princípio pode ser observado nas distintas seções do livro, com a única exceção da parte relacionada aos peixes, que se restringe às suas características exclusivamente nutricionais e os supostos efeitos causados por sua ingestão pelas pessoas.

Debra L. Stoudt apresenta um inventário de "feitiços" (incantations) contidos nas diferentes seções do Physica de Hildegard, sem, contudo, oferecer uma definição mais precisa deste conceito. De acordo com ela, "há

10 Não abordarei aqui as discussões em torno dos diferentes títulos que estes textos adquiriram no decorrer de sua história editorial ou as justificativas apresentada pelos diferentes editores para efetuar estas alterações. Nem, tampouco, a polêmica em torno dos manuscritos que atestam sua legitimidade autoral. Este tópico seria, de fato, indispensável caso se tratasse de Causae et Curae, do qual pouco ou nada restou dos manuscritos originais, mas que, ainda assim, podem ser com bastante segurança considerados textos de Hildegard. No caso de Pbysica, basta, para as intenções deste artigo, mencionar que a autoria de Hildegard é incontestável e seu conteúdo parece ter sido uma compilação dos trabalhos que a abadessa desenvolveu sobre esta temática entre os anos de 1151 e 1158. Cf. a introdução da tradutora Priscilla Throop na edição do Physica citada na bibliografia deste trabalho (p. 1-6), a minuciosa introdução elaborada por Barbara J. Newman para a edição do Scivias em português, também incluída na bibliografia abaixo (especialmente as páginas 23-36), e ainda o artigo de Debra L. Stoudt (2017, p. 252-257). 
quatorze feitiços relacionados às pedras, nove relacionados aos animais, seis referentes às árvores, e um para cada livro sobre as plantas e os elementos" (STOUDT, 2017, p. 265).

$\mathrm{Na}$ seção sobre as plantas, consideravelmente mais extensa do que as demais, Hildegard inicia com a pressuposição da sinergia entre ser humano e natureza que, diga-se de passagem, é um princípio essencial às práticas da magia: "Todos os elementos serviam à humanidade e, sentindo que o homem estava vivo, ocuparam-se no cuidado com a vida dele de todos os modos" (HILDEGARD, 1998, p. 9). Não obstante, as plantas estão divididas segundo sua natureza e os efeitos que seus poderes causam nas pessoas: "Através das ervas benéficas, a terra produz a variedade de poderes espirituais da humanidade e distingue entre eles; através das ervas daninhas, ela manifesta comportamentos prejudiciais e diabólicos" (HILDEGARD, 1998, p. 9).

Tanto no que diz respeito às plantas, quanto nas demais categorias incluídas no livro, Hildegard se mantém sempre próxima do princípio terapêutico do equilíbrio, oriundo da tradição oriental, que classifica todas as coisas pela sua natureza "quente ou fria", "seca ou úmida". As enfermidades, para ela, seriam decorrência de um desequilíbrio desses fatores no organismo, cuja causa poderia estar relacionada seja com disfunções biológicas ou com uma vida governada por vícios. ${ }^{11}$ Porém, além dessas características, algumas plantas também possuiriam traços que afetam o comportamento tanto de homens como de espíritos, conforme ela explica:

Algumas ervas possuem em si o poder dos aromas mais fortes ou a repugnância dos aromas mais amargos. Portanto, suprimem e controlam muitas doenças causadas por espíritos malignos. Também há ervas que têm em seu interior algo semelhante ao sumo dos elementos. Com elas, pessoas iludidas tentam buscar suas fortunas. O diabo ama estas ervas e se mistura com elas (HILDEGARD, 1998, p. 10).

O caso exemplar entre as plantas é a "mandrágora". Espécime consagrada tanto na literatura quanto na cultura popular quando o assunto é ritual de magia ou feitiçaria, a mandrágora também é muito relevante para os procedimentos da abadessa. De acordo com ela, a enorme similaridade da raiz desta planta com o corpo humano propicia uma "influência do diabo" mais significativa sobre esta planta do que as demais. Deste modo, explica, "os desejos bons ou maus de uma pessoa são alcançados por intermédio desta planta, tal como ocorreu antigamente com os ídolos que a humanidade produziu" (HILDEGARD, 1998, p. 33).

11 Para uma breve análise sobre as fontes e a natureza dos conhecimentos medicinais de Hildegard (cf. STOUDT, 2017, p. 258-259). 
Um ritual que envolvia a retirada da planta do solo e sua imersão imediata numa fonte de água corrente pelo período de um dia e uma noite garantia a neutralização de seus poderes "mágicos" e "fantasmagóricos". Do contrário, adverte a abadessa, se a planta fosse retirada do solo e deixada com os resíduos de terra grudados em suas raízes, tornar-se-ia propícia "para muitos atos injuriosos de magia e para superstições" (HILDEGARD, 1998, p. 33). Obedecidos os passos de purificação, a mandrágora estava apta para o uso em contrafeitiços amorosos e poderia funcionar até mesmo como vodu. No caso dos contrafeitiços, é interessante notar o paralelismo da descrição de Hildegard sobre quem deveria lançar mão da mandrágora e os efeitos desejados para as vítimas de magia erótica nos "Papiros Mágicos Gregos" (PMG). ${ }^{12} \mathrm{~A}$ abadessa prescreve:

Se um homem, através de magia ou do calor ardente de seu corpo, sofre de luxúria, deverá colher as raízes de uma mandrágora feminina, que deve ter sido purificada como mencionado. Deve atá-la entre seu próprio peito e umbigo por três dias e três noites. Após este período, deverá dividir as raízes em duas partes e manter uma parte amarrada em cada lado de sua virilha por três dias e três noites. Além disso, deverá pulverizar a mão esquerda desta mesma imagem [trata-se da raiz] e adicionar um pouco de cânfora a este pó. Comendo esta mistura, ela o curará (HILDEGARD, 1998, p. 34).

O mesmo se aplica às mulheres, testificando que ainda no século 12 a agência dos feitiços eróticos não poderia ser facilmente vinculada a um dos gêneros. A única diferença está no fato de que, no caso de as mulheres serem acometidas pelos sintomas descritos acima, a raiz deveria vir de uma mandrágora masculina e, ao invés da mão esquerda ser pulverizada, isso deveria ser feito com a mão direita da planta-imagem.

Por fim, após listar as inúmeras utilidades da mandrágora para o alívio de quase todo tipo de mazelas, bastando para isso que a pessoa ingerisse a parte da raiz correspondente à parte do próprio corpo afetada pela moléstia, Hildegard prescreve um rito para quem estiver "sempre triste e sempre em dificuldade", de modo que sinta seu coração fraco ou dolorido, sem especificar as causas. Neste caso, o sujeito deveria colher a mandrágora e, após seguir as mesmas recomendações quanto à purificação, coloca-la próxima de si na sua própria cama, de modo que sua transpiração pudesse aquecer a

12 Há muitos feitiços eróticos descritos nos PMG. Para a comparação da sintomatologia esperada nos papiros e aquela descrita por Hildegard, veja especialmente, PMG IV, 296-466 e PMG XXXVI, 333360. Para análises mais detalhadas de magias eróticas nos PMG, seus agentes, vítimas, contextos, rituais, usos etc., cf. dentre outros textos Matthew W. Dickie (2000), Eleni Pachoumi (2011, 2012, 2013) e David Frankfurter (2001). Para este artigo, os PMG citados foram baseados na versão de Hans Dieter Betz (1986), conforme consta na bibliografia. 
planta. Com isto feito, deveria dizer: "Deus, tu fizeste o ser humano do barro da terra, sem dor; agora eu coloco ao meu lado esta terra, que nunca fora pisada; do mesmo modo possa minha terra sentir aquela paz, assim como a criaste" (HILDEGARD, 1998, p. 34).

Curiosamente, Hildegard concede que a mandrágora seja substituída, numa raríssima exceção ao seu princípio de que as coisas criadas possuam em si um poder oculto revelado por Deus para usos específicos pelos humanos. No caso da pessoa que desejar realizar o ritual contra qualquer tipo de mazela não dispor de uma mandrágora para isso, poderá usar as primeiras brotações de raízes de uma árvore da família dos Fagus. "Felizmente, ela possui a mesma qualidade para estes propósitos", garante a monja. Todavia, para que tudo funcione como o esperado, é indispensável que o praticante pronuncie "as mesmas palavras novamente sobre as raízes" (HILDEGARD, 1998, p. 34).

A substituição de elementos mágicos considerados raros e difíceis de serem encontrados ou complexos demais para serem preparados, por outros mais simples e disponíveis, é uma concessão recorrente nos PMG e provavelmente seja consequência da popularização dos rituais antes restritos a um grupo social específico. Nestes casos, a ênfase também recai no zelo para com as partes faladas ou escritas dos rituais, as "fórmulas" e "voces magicae", sempre recomendadas com exatidão. Já na prescrição de Hildegard, além da substituição da mandrágora por outra planta mais acessível, é importante notar a designação do dito a ser proferido. Não se trata de dizer, no entanto, que haja em Hildegard qualquer coisa que remeta às voces magicae dos PMG, tecnicamente falando. De fato, a conjugação entre "planta" e "palavras" ou "oração" sugere a prática de um ritural de poder, no qual a similaridade da parte da planta ou "material mágico" com o corpo do paciente corresponde à semelhança dos eventos vividos pelas personagens mencionadas nas "palavras”, como ficará mais evidente no caso da comparação com Lázaro num ritual de cura de uma enfermidade da pele.

Por causa destas características presentes nos feitiços descritos no Physica, a compreensão de seus sentidos não é alcançada pelo recurso a hermenêuticas que se fundamentam apenas na aproximação entre tais rituais e os conceitos tradicionais de "medicina" e "teologia", por mais competentes que sejam estas hermenêuticas. Este parece ser o caso do artigo já mencionado de Debra Stoudt (2017). Apesar da competência da autora em traçar um possível itinerário do conhecimento médico "científico" incipiente, disponível e acessível para Hildegard, na região em que ela viveu, durante o século 12, e demonstrar como este conhecimento se articula com o conteúdo terapêutico do Physica, sendo complementado por práticas preservadas também no 
âmbito da cultura popular, Stoudt não avança para considerações sobre a magia como recurso para curar as mais diversas mazelas, desde a Antiguidade. Pelo contrário, limita-se a classificar as prescrições da abadessa como sendo fontes parciais da "natureza da medicina monástica do século 12", por mais que reconheça nelas a introdução de um elemento central para a teologia de Hildegard, a saber: "a percepção da relação entre o mundo natural e o mundo que está para além dele” (STOUDT, 2017, p. 259). O que falta à Stoudt é exatamente a atenção ao substrato da cultura popular que nunca desapareceu do contexto de Hildegard, como foi notado anteriormente, e no qual existe uma imbricação indissociável de religião, medicina e magia.

Não obstante, quando analisa a obra de uma perspectiva teológica, Stoudt também se satisfaz com a separação dogmática clássica entre "magia" e "milagre", aceitando sem qualquer crítica a designação de Hildegard como sendo usada por Deus e, portanto, operadora de "milagres" e não de "magia", que seria uma prática associada ao diabo (STOUDT, 2017, p. 270). É certo que Stoudt não ignora as complexidades envolvidas na conceituação de "magia" e "milagre", pois, logo no início de seu texto, ela faz a seguinte afirmação:

A reputação de um ato ou evento como mágico ou milagroso depende em parte dos indivíduos envolvidos, assim como daqueles que reportam ou recontam estes atos. Como Benedicta Ward observa: "Magia era ... a acusação imposta aos milagres não aceitáveis pelos outros grupos. Os milagres de hereges são condenados como magia". $\mathrm{Na}$ designação de um ato como magia ou milagre, a ortodoxia esposada pelo indivíduo envolvido pode ter mais relevância do que o ato em si mesmo (STOUDT, 2017, p. 252).

O equívoco de Stoudt consiste exatamente em não se perguntar pelas origens dos sentidos atribuídos por Hildegard aos diversos elementos pressupondo apenas a tradição médica e teológica da monja como sendo suas fontes -, nem comparar o conteúdo dos feitiços da abadessa com o percurso da relação entre a cristianização da Alemanha, a partir do século 10, e as religiões pagãs amplamente difundidas na cultura popular. Assim como ocorre com Newman, também Stoudt se deixa levar pela transmissão de conhecimentos exclusivamente processada por agentes das instituições cristãs, não percebendo o caráter fronteiço das interações culturais de Hildegard e suas articulações com a cultura popular.

Este parentesco fica bastante claro quando Hildegard prescreve um feitiço relacionado ao asno, animal muito frequente nos rituais de magia na Antiguidade. Nos escritos da abadessa, devem recorrer ao feitiço envolvendo o asno aquelas pessoas que sofrem de um certo tipo de paralisia acompanhada de tremores involuntários (palsy), cujos sintomas estariam relacionados com as fases lunares. 
Todavia, curiosamente, a preparação do ritual não envolve qualquer parte do corpo do animal vivo ou morto, sendo que sua menção é justificada apenas pelo fato de sua carne ser considerada "fétida" e seu comportamento "estúpido". Se esta dispensa sugere algo distinto do que ocorre nos rituais mágicos contidos, por exemplo, nos PMG, a ambiência e os ditos a serem observados novamente remetem às práticas antigas. $\mathrm{O}$ feitiço prescrito pela abadessa orienta que por três dias consecutivos e por três vezes em cada dia, o paciente seja levado até o lugar no qual um asno tenha sido morto - por causas naturais ou violentas - ou tenha rolado sobre a terra. Lá, ele deveria ser deitado e, se possível, adormecer. Em seguida, o praticante do feitiço é orientado a segurar a mão direita do paciente e proferir algumas frases relacionadas à narrativa bíblica da ressurreição de Lázaro, como segue:

Lázaro dormiu e descansou, depois se levantou. Assim como ele foi levantado por Cristo da fétida imundície, levante-se desta perigosa doença e modos febris oscilantes, juntamente com aquelas coisas que Cristo, que se assenta acima, reuniu a si mesmo quando, antecipando que redimiria os povos de seus pecados, despertou a Lázaro (HILDEGARD, 1998, p. 212).

Por fim, é importante analisar o uso que Hildegard faz das "pedras" - mais precisamente as "joias" - para ilustrar mais uma vez as vizinhanças e encruzilhadas entre teologia, medicina e magia em suas obras. Exemplos paradigmáticos são a incrustação de jacinto numa cruz feita em um pão de centeio que serviria como contrafeitiço a ser empregado nas pessoas que se tornaram loucas por consequência de práticas mágicas lançadas contra elas (HILDEGARD, 1998, p. 139); o emprego da safira para elaboração de um amuleto para exorcismo ou realização de um feitiço contra "paixões incômodas", incitadas nos indivíduos pelo demônio mesmo que sem o incurso de "magia ou invocação de demônios"; a fricção de um sárdio ao redor das coxas de uma parturiente oprimida pela dor e com dificuldades para dar à luz uma criança (HILDEGARD, 1998, p. 142-144); dentre outros usos para diferentes joias.

Para Hildegard, as joias parecem ter alguma energia ou poderes em si mesmas. Não basta, contudo, reputar esta intuição ao seu modo de pensar teologicamente que, de resto, se enquadra no que ficou conhecido como "teologia sapiencial". O que ela faz - e isso é fundamental para a percepção da vizinhança de seu pensamento com a magia - é acomodar os poderes e usos das pedras na moldura da narrativa mítica judaico-cristã da criação, de modo muito semelhante a alguns feitiços que buscavam fazer participar o praticante no contexto mítico dos deuses invocados nos papiros gregos e 
na literatura mágica disponível em seus dias. Conforme explica Kieckhefer, discorrendo sobre o mito de Odin nas sagas nórdicas largamente difundidas no século 12:

O que este mito revela mais vividamente do que as demais sagas é um senso de como a magia exige uma preparação ascética: aqui, como em outras culturas europeias, as forças mágicas fluem de alguém que tenha performado disciplinas heroicas; controlado o corpo e fortalecido a alma; e, com esforço intenso da vontade, conquistado acesso às energias de outra forma escondidas (KIECKHEFER, 2014, p. 53).

Logo na abertura da seção, Hildegard justifica que o diabo abomina as pedras preciosas, porque elas lhe trazem à memória seu estado de glória original - quando era "vestido de pedras preciosas" - e seu castigo pelo orgulho de desejar ser como Deus - sendo despido de suas "vestes" e lançado ao lago de fogo e enxofre (HILDEGARD, 1998, p. 138). Esta peculiaridade confere às joias imunidade quanto aos usos malignos possíveis aos outros elementos, como a mandrágora, por exemplo. A abadessa explica que muitas coisas podem ser feitas com as joias, todavia "apenas ações boas, honestas e que sejam benéficas aos seres humanos" (HILDEGARD, 1998, p. 138).

Mesmo assim, alguns usos específicos demandam que se pronunciem as fórmulas "mágicas", evidentemente envoltas em roupagem teologicamente adequadas à dogmática cristã. Então, no caso do jacinto, além da cruz a ser recortada na casca do pão, o praticante deveria pronunciar: "Queira Deus, que arrancou todas as pedras preciosas do demônio quando este subverteu Seu comando, retirar de ti agora, N., toda confusão e todas as palavras mágicas, e te libertar da dor desta loucura" (HILDEGARD, 1998, p. 140). A letra "N" corresponde ao espaço para se incluir o nome da pessoa que está sofrendo do mal a ser extirpado pelo feitiço. Essa estrutura é muito comum nos PMG e sugere que o feitiço de Hildegard provavelmente também pode ter recebido uma forma escrita, o que novamente a aproxima da prática da magia em seu contexto, pois, de acordo com Kieckhefer, os testemunhos literários sobre a prática mágica na baixa Idade Média indicam que "tanto para um mago divino quanto para um humano, a magia é uma força intimamente ligada com a escrita" (KIECKHEFER, 2014, p. 53).

Uma última observação é relevante. Trata-se da permissão para que o feitiço contra "paixões incômodas" - no qual uma certa quantidade de vinho deveria ser derramada três vezes sobre uma safira e coletada para ser posteriormente ingerida pelo homem ou mulher molestada por tais paixões - fosse realizado por terceiros. Também neste feitiço, há uma fórmula que relembra a queda do diabo e sua expulsão do paraíso, ordenando que o 
mesmo aconteça com a "paixão indesejada". Porém, Hildegard acrescenta que se a mulher não desejasse realizar o feitiço, então "outra pessoa para quem aquele amor fosse um problema deveria realizá-lo" (HILDEGARD, 1998 , p. 143). O mesmo valia para os homens. Esta permissão remete ao uso comum da magia nos três primeiros séculos da era cristã para se manter os acordos nupciais, sempre ameaçados por outros "feitiços", bem como às práticas da cultura popular para lidar com assuntos de impotência sexual entre os homens. Este tema, de acordo com Rider, "pode ser usado para explorar a relação entre 'cultura popular' e 'cultura erudita" na Idade Média (RIDER, 2006, p. 3). E, como foi visto, a obra de Hildegard pode oferecer um interessante ponto de partida.

\section{Considerações finais}

Quando Bento XVI finalmente promulgou a canonização de Hildegard von Bingen e sua titulação como "doutora da Igreja", atestando com isso a origem milagrosa de suas curas e exorcismos e a retidão seus ensinamentos, concluía-se, de modo favorável, a reivindicação iniciada já nos anos que sucederam sua morte, em 1179, e a abadessa tornara-se, enfim, sancta et magistra. O que ainda permanece teimosamente num estado de inconclusão, desde antes dos dias vividos por Hildegard, são as trocas não-autorizadas entre "religião" e "magia", "milagre" e "feitiçaria", "santas" e "bruxas".

Mesmo sob a benção apostólica de Eugênio III para continuar escrevendo e publicando suas visões a respeito de conteúdos da Teologia cristã, a atuação e interação cultural de Hildegard seria marcada por uma espécie de "tradução" e "simbiose" da religião popular e do cristianismo eclesiástico. Se, por um lado, ela condena a prática da magia em textos "inspirados" como o Scivias, por outro, atravessa esta fronteira subrepticiamente quando prescreve magia como cura e terapia no Physica.

Certamente, um recorte que privilegie apenas as obras visionárias e declaradamente teológicas de Hildegard evidenciará a extraordinariedade e particularidade de sua experiência religiosa, bem como a autoridade e criatividade de sua sistematização dogmática cristã. E dará a sensação de que as práticas "mágicas", "obscuras" e "supersticiosas", dos primeiros séculos da era cristã já seriam, durante o século 12, “ilusões" devidamente superadas pelo labor teológico. Se ainda pudessem ser lembradas, era por obra da insistência diabólica em enganar e desviar os indivíduos da reta doutrina.

Porém, quando as obras da magistra et sancta Hildegard são vistas em seu conjunto mais amplo, nota-se que o sofrimento humano extravasa as verti- 
calizações ortodoxas e exige das pessoas uma transposição das fronteiras do condomínio teológico para que se explore a vizinhança, imiscuindo-se nas encruzilhadas presentes desde sempre no contexto da cultura e religião popular. É assim que a magia é "batizada" e seus efeitos novamente reabilitados para alívio dos pobres corpos. Parafraseando uma afirmação recorrente de Hildegard no Physica, sempre ao final de prescrições flagrantemente mágicas, como que para atestar sua fidelidade teológica: "A não ser que Deus", esse latifundiário sempre ciumento, "assim não o queira...”.

\section{Referências bibliográficas}

BETZ, Hans Dieter (Ed.). The Greek Magical Papyri in translation: including the Demotic Spells. Chicago \& London: The University of Chicago Press, 1986.

BINGEN, Hildegarda de. Libro de las obras divinas. Tradução de María Isabel Flisfisch. Barcelona: Herder, 2009.

CLASSEN, Albrecht. Magic in the Middle Ages and the Early Modern Age - literature, science, religion, philosophy, music, and art: an introduction. In. CLASSEN, Albrecht (ed). Magic and magicians in the Middle Ages and the Early Modern Time: the occult in Pre-Modern sciences, medicine, literature, religion, and astrology. Berlin; Boston: Walter de Gruyter GmbH, 2017, p. 1-108.

DEPLOIGE, Jeroen. Hildegard de Bingen y su libro Scivias: ideologia y conocimientos de uma religiosa del siglo XII. Revista Chilena de Literatura, n. 55, p. 85-102, 1999. Disponível em https://revistaliteratura.uchile.cl/index.php/RCL/article/view/39218/40845. Acesso em 02 mai 20.

DICKIE, Matthew W. Who practised love-magic in Classical Antiquity and in the Late Roman World? In: The Classical Quarterly, v. 50, n. 2, p. 563-583, 2000. Disponível em http://www.jstor.org/stable/1558912. Acesso em 20 abr 2020.

FRANKFURTER, David. The perils of love: magic and countermagic in Coptic Egypt. Journal of the History of Sexuality, v. 10, n. 3, p. 480-500, julho/outubro de 2001. Disponível em https://www.jstor.org/stable/3704757?seq=1. Acesso em 20 fev 2020 .

FRASER, Kyle A. The contested boundaries of "Magic" and "Religion" in the Late Pagan Monotheism. In: Magic, Ritual, and Witchcraft, vol. 4, n. 2, p. 131-151, 2009. Disponível em https://muse.jhu.edu/article/364065. Acesso em 20 fev 2020. GALLE, Christoph. Zum Umgang mit Zauberern im Rahmen frühmittelalterlicher Missionsanstrengungen. In: CLASSEN, Albrecht (ed). Magic and magicians in the Middle Ages and the Early Modern Time: the occult in Pre-Modern sciences, medicine, literature, religion, and astrology. Berlin; Boston: Walter de Gruyter GmbH, 2017, p. 231-257.

HILDEGARD, Saint. Hildegard von Bingen's Physica: the complete translation of her classic work on health and healing. Tradução do latim por Priscilla Troop. Rochester: Healing Arts Press, 1998. 
HILDEGARDA, Santa. Scivias: conhece os caminhos do Senhor. Tradução de Paulo Ferreira Valério. São Paulo: Paulus, 2015.

KIECKHEFER, Richard. Magic in the Middle Ages. 2. ed. Cambridge: Cambridge University Press, 2014.

NEWMAN, Barbara J. Hildegard of Bingen: visions and validations. Church History, v. 54, n. 2, p.163-175, jun 1985.

NEWMAN, Barbara. Sisters of Wisdom: St. Hildegard's theology of feminine. Berkeley; Los Angeles: University of California Press, 1997.

PACHOUMI, Eleni. Eros and psyche in erotic magic. Classica et Medievalia, v. 62, p. 39-49, 2011.

PACHOUMI, Eleni. Eros as disease, torture and punishment in magical literature. Symbolae Osloenses, v. 86, n. 1, p. 74-93, 2012. Disponível em http://dx.doi.org./10.10 80/00397679.2012.696949. Acesso em 20 abr 2020.

PACHOUMI, Eleni. The erotic and separation spells of the Magical Papyri and defixiones. Greek, Roman and Byzantine Studies, v. 53, n. 2, p. 294-325, 2013. Disponível em https://doaj.org/article/df66c8a5696448e4a21bd9f916950ddf. Acesso em 20 fev 2020.

RIDER, Catherine. Magic and impotence in the Middle Ages. New York: Oxford University Press, 2006.

STOUDT, Debra L. The Medical, the magical and the miraculous in the healing arts of Hildegard of Bingen. In: KIENZLE, Beverly Mayne; FERZOCO, George; STOUDT, Debra L. (Eds.). A Companion to Hildegard von Bingen. Leiden; Boston: Brill, 2014, p. 249-270.

OLIVEIRA, Maria Carmen Goes Martiniano de. A peregrinação da alma no Scivias de Hildegard de Bingen: criação, queda, redenção e salvação. História (São Paulo), Marília/ Franca, v. 32, n. 2, p. 209-240, jul.-dez. 2013. Disponível em www.scielo.br/pdf/his/v32n2/ a11v32n2.pdf. Acesso em 03 set 19.

Submetido em: 30-4-2020

Aceito em: 8-5-2020 